\title{
1 \\ THE STRUCTURE OF SYSTEMS ANALYSIS
}

If you ask the average systems analyst to describe and define the work he does, you will probably receive a very vague answer. This is not because his work is particularly complex or difficult to describe (it is Nor, as this book attempts to show), but simply because most systems analysts themselves do not have a very clear idea of the structure of their task. They are usually heavily overworked and manage to do their daily work because in most companies there is always a backlog of systems work which is clearly defined due to its urgency. So they follow a series of short-term goals rather than a methodology of systems analysis.

This book purports to show that there is a methodology of systems analysis, that systems analysis itself can be analysed into clearly recognizable steps. Each of these steps can be defined in terms of activities, so that one obtains a structure for the task. There is nothing mysterious about this. Indeed, the authors feel that the book will have been a success if it removes some of the mystique which surrounds systems analysis.

It is not claimed that every aspect of systems analysis can be defined in terms of the six broad steps described in this Part, because there are a number of other important aspects, like standards and documentation, which relate to all the steps. These are treated later in the book. Nevertheless, if a novice systems analyst follows the six steps described hereafter, on completion of a given task he will have done a thorough job of systems analysis.

The six main steps are :

1 System Project Selection

2 Feasibility Study

3 Definition Phase

4 Design Phase

5 Implementation Phase

6 Evaluation Phase

We will first describe each of these separately and then relate them to each other, to show how together they form a carefully ordered approach. 